\title{
To Investigate the Effects of Process Parameters on Welding Current of a MIG Welding Power Source
}

\author{
Deeksha Narwariya \\ Student, M.Tech, MPAE Division \\ Netaji Subhas University of Technology \\ New Delhi, India
}

\author{
Dr. Pradeep Khanna \\ Associate Professor, MPAE Division \\ Netaji Subhas University of Technology \\ New Delhi, India
}

\begin{abstract}
Metal inert gas welding is an extensively used joining process in food processing, automobile and general fabrication industries. The process is preferred because of its portability versatility and ability to get automated, making it suitable for mass producing units. So the process can weld a large variety of material for which suitable filler material is available. As a general perception it is believed that for power source used in a MIG welding, the welding current is purely decided by the wire feed rate set for a particular application. However a series of trial runs have revealed that welding current solely does not depend upon wire feed rate. Instead it varied with voltage and nozzle to plate distance. This fact if ignored could lead to significant errors while studying the impact of welding parameters on various aspects of weld produced. The authors therefore felt the need to establish the link between the process parameters and the welding current so that the investigations based on these parameters can be carried out accurately. A mathematical model has been developed between the response parameter which is current (amp) and input parameters which are wire feed rate $(\mathrm{m} / \mathrm{min})$, voltage (volts), and nozzle to plate distance $(\mathrm{mm})$ by using Taguchi's approach. L8 array has been used to develop the model and graphical responses are used to analysis the results.
\end{abstract}

Keywords - MIG welding; power source; welding current; input parameters; mathematical model.

\section{INTRODUCTION}

MIG welding technique is suitable for joining materials during the fabrication of structures. It can be used for nonferrous welding as well. The process can be used in semiautomatic, automatic or robotic version. The process can very well be used in mass production units because of its capability of producing repeatable joints. An arc is initiated between the end of a wire electrode and specimen, forming a weld pool by melting them. The gases used for shielding in the process are argon (Ar), helium ( $\mathrm{He}), \mathrm{CO}_{2}$ or a mixture of these gases for optimized results as far as the quality of weld is concerned [1,2].Argon is preferred for the welding of thin steel plates as its arc is less hot and stable at less powers as well. Helium on the other hand is used where thick plates are to be welded as this gas produces hot arc which is stable at high currents, but the gas is quite costly. The mixture of these gases on the other hand provides the benefits of all the constituents and are generally preferred. The quality of weld produced is very competitive in strength, aesthetics and cleanliness with no necessity for after weld cleaning operations as the process uses no flux. The process can give high deposition rates and suitability for all position welding. There are a number of welding input parameters which are generally set prior to welding a material to have some desirable characteristics of the final weld. These parameters are the welding current, wire feed rate (WFR), voltage (V), nozzle to plate distance (NPD) and torch angle. These parameters will have an effect on the weld attributes to a great extent [3]. Upon conducting a series of experiments it was found that the welding current, a very important input parameter depends not only on wire feed rate as a general thought, but also is getting affected by the variation in other parameters as well. This wrong belief must be clarified so that some serious errors may not creep in the research investigations where all these parameters are involved. This can be done by establishing a mathematical equation between WFR, NPD, voltage and welding current. In the present case the other parameters found to have effect on welding current are voltage and the nozzle to plate distance. Now, in order to calibrate a power source, a mathematical relation is required to be established between these parameters is of significance as otherwise there is a possibility of making erroneous inferences about a process. This study is done to calibrate a flat V-I characteristic power source by developing an analytical model between the process parameters and the response parameter which is welding current. To conduct the experiments in a structured way, so as to reach a logically reliable conclusion it was felt to use some technique of experimental design. Many options are available for the purpose like factorial design and Taguchi method. After referring to a number of literature works, it was concluded that Taguchi's approach would be appropriate as the number of experiments included are less and the L8 model would suit the present investigative work. Taguchi's method is capable of developing a robust design which gives protection from the noise factors. Taguchi's method provides a robust methodology for designing the experiments where the effects of uncontrollable parameters called noise factors is taken care of by eliminating their effect [4]. Taguchi's approach is used for developing the model according to which the experiments shall be conducted. In order to check the acceptability of the developed model, inspection of variance (ANOVA) technique was used where F-ratio and R-ratio were computed and collated with their listed values for the concerned degree of freedom. if the computed value of R-ratio is greater than its listed value and If the computed value of F-ratio is lower 
than its listed value, then the model can be termed as adequate. 3-D surface graphs provided by the MINITAB software were then used to analyze the collective effects of the input parameters on the response parameter.

\section{EXPERIMENTAL SETUP}

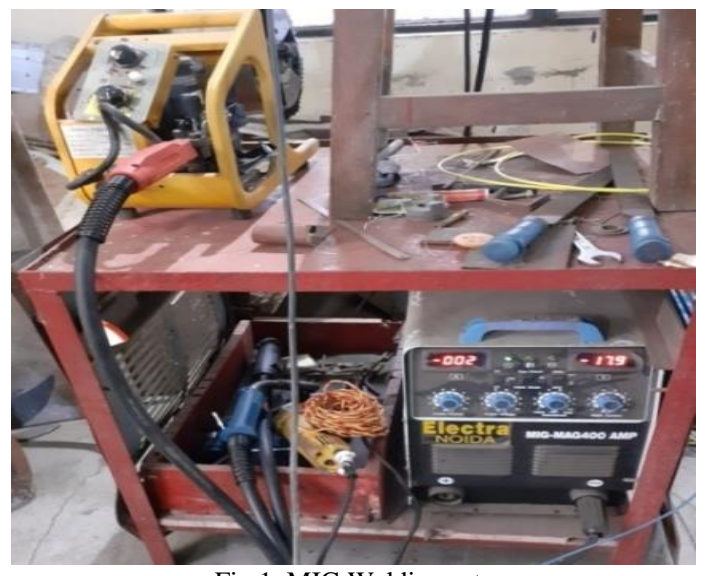

Fig.1. MIG Welding setup

In the present investigative work, a constant voltage power source with flat V-I characteristics was used with rated current output as $400 \mathrm{amp}$ and voltage range 16-36 v. A mechanized feeding unit was used to ensure repeatability of results and to ensure constant welding speed. A Variable frequency drive unit was used to derive step less control of the welding speed. The welding speeds available on the unit are $0-50 \mathrm{~cm} / \mathrm{min}$. Copper coated solid mild steel wire of $1.2 \mathrm{~mm}$ diameter, used as filler with DCEP. Industrially pure grade of argon gas was used for shielding at a rate of $16 \mathrm{lpm}$. The complete welding set-up used for the present study is shown in the figure-1

\section{METHODOLOGY OF WORK}

The following steps were observed while carrying out the investigative work.
A. Recognizing the process parameters
B. Estimation of the working constraints of the selected parameters
C. Establishment of a design matrix
D. Conduction of the design matrix experiments
E. Generation of the mathematical model
F. Explaining the reasonability of the developed model
G. reviewing the outcomes

\section{A. Recognizing the process parameters}

On the basis of trial runs conducted, it was found that WFR, voltage and NPD affects the current. Although, there is no significant effect of gas flow rate and welding speed. Torch to work piece inclination, gas flow rate and table speed was kept $90^{\circ}, 151 \mathrm{pm}$ and $30 \mathrm{~cm} / \mathrm{min}$ throughout the experiment.

\section{B. Estimation of the working constraints of the selected} parameters

Once the significant input parameters were found, their working limits were determined by conducting trials by varying one parameter over its range and keeping others at an average level, keeping in view the quality of weld is within acceptable range as far as bead continuity and any surface defect is concerned. These limits are summarized in table-1 below. Two levels of each factor were considered with lower coded as -1 and the upper level as +1

TABLE-1 UPPER AND LOWER LIMIT OF PARAMETERS

\begin{tabular}{|l|l|l|l|l|}
\hline PARAMETER & UNIT & SYMBOL & \multicolumn{2}{|c|}{ LIMITS } \\
\cline { 4 - 5 } & & & -1 & +1 \\
\hline Wire feed rate & $\mathrm{m} / \mathrm{min}$ & WFR & 4 & 6 \\
\hline $\begin{array}{l}\text { Nozzle to plate } \\
\text { distance }\end{array}$ & $\mathrm{Mm}$ & NPD & 10 & 20 \\
\hline Voltage & Volts & $\mathrm{V}$ & 18 & 28 \\
\hline
\end{tabular}

\section{C. $\quad$ Establishment of a design matrix}

Design matrix was developed by MINITAB software with a total numbers of eight runs in two replicates each. The combinations of these eight runs are given in table- 2 .

TABLE-2 COMBINATION OF UPPER AND LOWER LIMITS FOR DIFFERENT INPUT PARAMETERS

\begin{tabular}{|l|l|l|l|}
\hline S.NO. & WFR & V & NPD \\
\hline 1 & -1 & -1 & -1 \\
\hline 2 & -1 & +1 & +1 \\
\hline 3 & -1 & +1 & -1 \\
\hline 4 & +1 & -1 & +1 \\
\hline 5 & -1 & -1 & +1 \\
\hline 6 & +1 & -1 & -1 \\
\hline 7 & +1 & +1 & -1 \\
\hline 8 & +1 & +1 & +1 \\
\hline
\end{tabular}

The weld beads laid on different specimen at the combinations given in table- 2 by bead on plate technique are shown in fig. 2 below

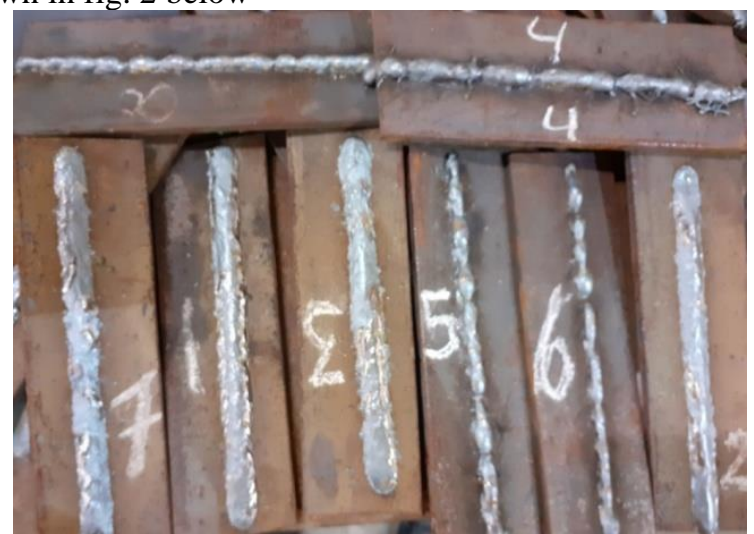

Fig. 2. Welding beads for different combination formed by MIG Welding

D. Conduction of the design matrix experiments The experiments were conducted with all the combinations in two replicates as suggested by the design matrix in a random order These experiments were conducted to ensure the elimination of systematic error, if any. The value of the welding current was recorded and is expressed in the table-3. 
TABLE-3 WELDING CURRENT OBSERVATIONS

\begin{tabular}{|c|c|c|c|c|c|c|}
\hline \multirow[t]{2}{*}{ S.N } & \multirow[t]{2}{*}{ WFR } & \multirow[t]{2}{*}{$\begin{array}{c}\text { Voltag } \\
\mathrm{e}\end{array}$} & \multirow[t]{2}{*}{ NPD } & \multicolumn{2}{|c|}{$\begin{array}{l}\text { Observed } \\
\text { Welding } \\
\text { Current } \\
\text { (Amp) }\end{array}$} & $\begin{array}{l}\text { Average } \\
\text { Welding } \\
\text { Current }\end{array}$ \\
\hline & & & & I1 & $\mathrm{I} 2$ & $(\mathrm{I} 1+\mathrm{I} 2) / 2$ \\
\hline 1 & -1 & -1 & -1 & 82 & 83.5 & 82.75 \\
\hline 2 & -1 & +1 & +1 & 130 & 127.5 & 128.75 \\
\hline 3 & -1 & +1 & -1 & 78.5 & 73.5 & 76 \\
\hline 4 & +1 & -1 & +1 & 83 & 82.5 & 82.75 \\
\hline 5 & -1 & -1 & +1 & 104.5 & 103.5 & 104 \\
\hline 6 & +1 & -1 & -1 & 66.5 & 72.5 & 69.5 \\
\hline 7 & +1 & +1 & -1 & 116.5 & 121 & 118.75 \\
\hline 8 & +1 & +1 & +1 & 104.5 & 109 & 109.25 \\
\hline
\end{tabular}

\section{E. $\quad$ Generation of the mathematical model}

The mathematical expression generated by MINITAB software is given below which includes the effect of individual terms and the interaction terms.

Welding Current $=-12.75+95.75 \mathrm{WFR}+39.50 \mathrm{NPD}+$ 38.25Voltage - 39.75WFR * NPD - 31.75WFR * Voltage -

28.25NPD $*$ Voltage $+21.75 \mathrm{WFR} *$ NPD $*$ Voltage

F. $\quad$ Explaining the reasonability of the developed model ANOVA analysis was done to examine the reasonability of the developed model as shown in table-4. The computed Fratio values are lower than the listed values thereby suggesting the adequacy. Secondly, the higher value of Rsquare and adjusted R-square also suggest the acceptability of the developed model.

\begin{tabular}{|l|l|l|l|l|l|}
\hline Source & DF & Adj MS & Adj SS & P-Value & F-Value \\
\hline Regression & 3 & 1062.28 & 3186.84 & 0.002 & 44.98 \\
\hline WFR & 1 & 2803.13 & 2803.13 & 0.000 & 118.69 \\
\hline NPD & 1 & 367.88 & 367.88 & 0.017 & 15.58 \\
\hline voltage & 1 & 15.82 & 15.82 & 0.459 & 0.67 \\
\hline Error & 4 & 23.62 & 94.47 & & \\
\hline Total & 7 & \multicolumn{7}{|c|}{3281.30} & & \\
\hline
\end{tabular}

The probability plot produced by the software is shown in fig. 3 below. It is evident from this plot that all the points are lying near the central line with a random pattern. This plot further substantiates the claim for reasonableness of the developed model.

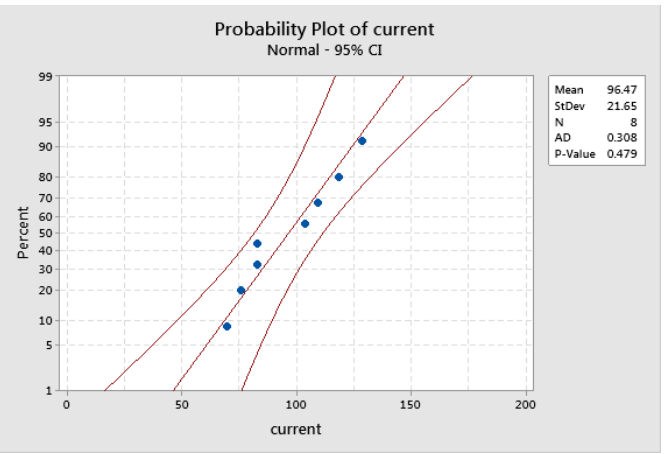

Fig.3. Probability plot

\section{G. Reviewing the outcomes}

The graphical results generated by the software are given in figures 4-7. These results are explained under two subheadings namely; main effects and interactive effects.

i) Main effects of input parameters on welding current Main effects of WFR, NPD and voltage are shown in fig. 4 below. It can be seen that as WFR is increased the current increases. The reason for this is that constant voltage type power source where a voltage is proportional to the arc gap. Now in-order to maintain this arc gap, if the WFR is increased, the welding current also increase to burn more wire readily to maintain the original arc gap. This feature of the power source is called self regulation of the welding arc and plays an important role while performing automatic welding. The current is found to decrease with the increase in voltage. The probable reason for this could be that when voltage is increased, the arc gap is also increased as both are proportional. In order to maintain larger arc gap, the burn-off rate must be reduced for which the current needs to be reduced. With the increase in NPD, the current is found to decrease, the probable explanation for this could be that with the increase in NPD the length of un-melted filler wire is increased which increases the resistance of the path thereby reducing the current for the same voltage.

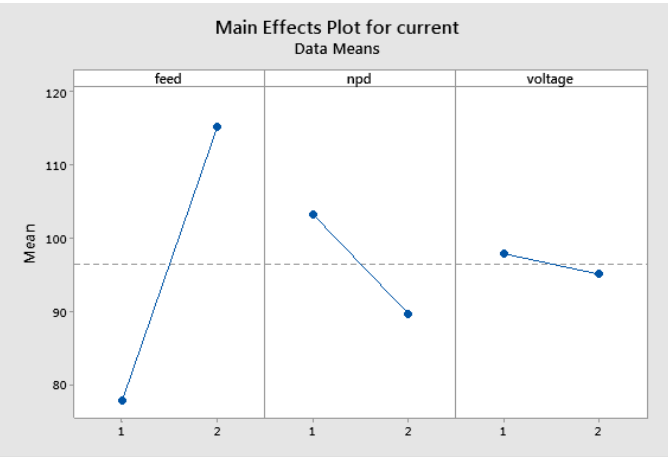

Fig. 4. effect of WFR, NPD and Voltage on current

ii) Collective effects of input parameters on welding current

The interactive effects of input parameters which are nozzle to plate distance, voltage and wire feed rate on welding current are given in fig. 5-7.

a) Collective effects of voltage and NPD on welding current

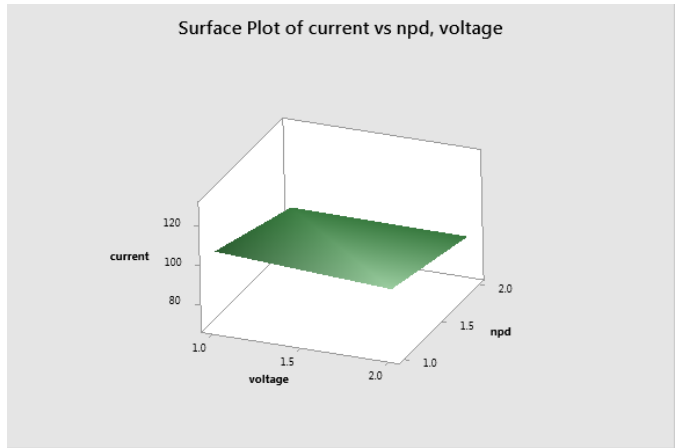

Fig. 5. Collective effects of voltage and NPD on welding current 
The above fig. 5 shows the Collective effects of NPD and voltage on welding current. It can be seen that for all the values of voltage, the current reduces with the increment of NPD for the reason explained in the previous section. There however seems to be a slight reduction in the current with the increment of voltage which is in line with the explanation given in the previous section 3.7.1.

b) Collective effects of voltage and WFR on welding current

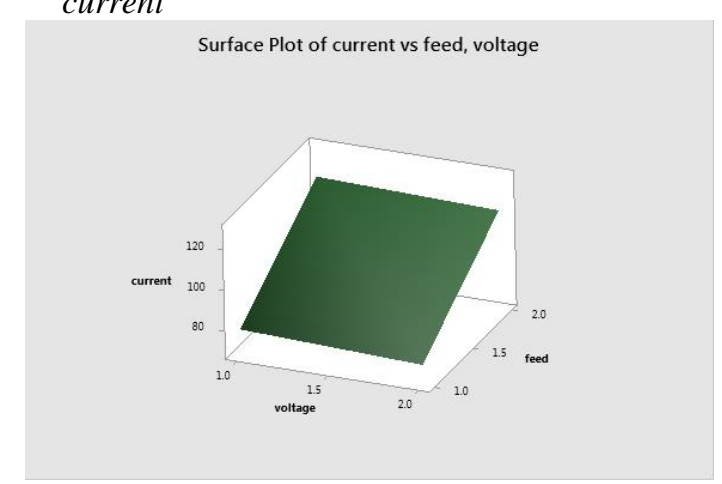

Fig. 6. Collective effects of voltage and wire feed rate on welding current The above fig. 6 shows the collective effects of WFR and voltage on welding current. It can be deduced that for all values of voltage, there is an increment in current with the increment of WFR for the reason explained in the previous section. There however seems to be a slight reduction in the current with the increment in voltage which is in line with the explanation given in the previous section 3.7.1

\section{c) Collective effects of WFR and NPD on welding current}

The fig. 7 shows the Collective effects of NPD and WFR on welding current. It can be seen that for all value of NPD, the current rises with the increment of WFR for the reason already explained. There however seems to be a slight reduction in the current with the increment in NPD which is in line with the explanation given in the previous section 3.7.1

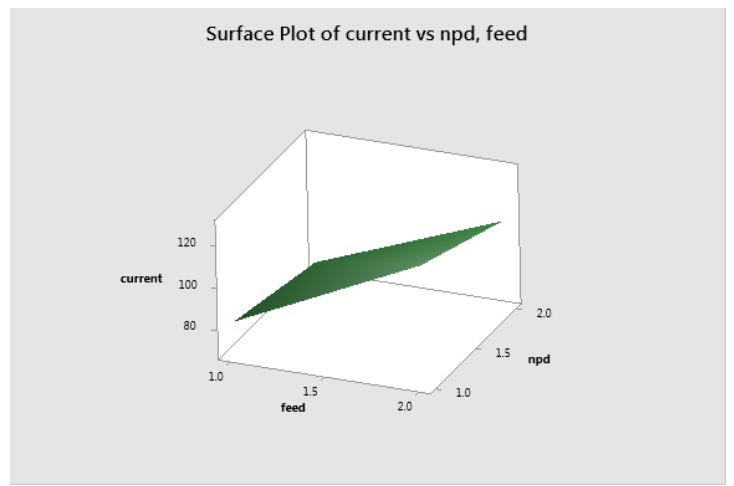

Fig. 7. Collective effects of wire feed rate and NPD on welding current

\section{CONCLUSIONS}

1. Taguchi's approach is found to be appropriate to investigate the present case.

2. The welding current has been found to get increased with the increment in wire feed.

3. The value of welding current reduces slightly with the increment in voltage.

4. The welding current reduced insignificantly with the increment in NPD.

\section{REFERENCES}

[1] Mahor N, Sharma T and Singh R, Study Of MIG Welding Process With Different Type Technique: A Review,4(2017)1-5.

[2] Misra B, Panda R.R and Mohanta D.K, Metal Inert Gas(MIG) Welding Parameters Optimization, 637(2014)1-3.

[3] Kumar C.L, Vanaja T, Dr. Murti KGK , Optimization Of MIG Welding Process Parameters For Improving Welding Strength Of Steel. 50(2017)26-33.

[4] Packianather, M.S, Drake, P.R. and Rowlands, H., "Optimizing the parameters of multilayered feed forward neural networks through Taguchi's Design of Experiments". Quality and Reliability International, Vol. 16, pp. 461-473, 2000.

[5] ESAB, MIG Hand book, 1994.

[6] Khanna P, Maheshwari S, "Effects of Wire Feed Rate, Voltage and Nozzle to Plate Distance on Welding Current in a MIG Welding Process". Proceedings, Vth International Symposium on "Fusion of Science \& Technology", (2016)305-310.

[7] Patil S. R, Waghmare C. A, Optimization Of MIG Welding Parameters For Improving Strength Of Welded Joints .4( 2013)1-3. 